\title{
The advanced $p-y$ method for analyzing the behaviour of large- diameter monopiles supporting offshore wind turbines
}

\author{
William F Van Impe ${ }^{1, *}$, and Shin-Tower Wang ${ }^{2}$ \\ ${ }^{1}$ Professor Emeritus, Ghent University, Laboratory of Geotechnics, and AGE bvba Geotechnical Consultants, Belgium \\ ${ }^{2}$ President, Ensoft, Inc/Lymon C. Reese and Associates, Austin, Texas, USA
}

\begin{abstract}
The analyses of monopile foundations have been heavily based on the p-y response curves (to represent lateral soil resistances) published by API RP 2GEO (2011) and DNV (2013), which are proven reliable and applicable for piles with smaller diameters that were normally used for jacket structures in the offshore industry. However, concerns have been raised about the validity of semi-empirical p-y criteria for large-diameter piles. Wind turbine monopiles have a significantly larger diameter and smaller length to diameter ratio than typical piles used for offshore structures. The ratio of the length to the diameter for a monopile typically is also significantly smaller than those used in the API load tests. Therefore, the response of a monopile may be more like a rigid rotation, with components of resistance mobilized at the tip and axially along the sides as it rotates. This behaviour is in contrast to long slender piles that respond to lateral loading in bending rather than rotation. The objective of this paper is to analyze the factors that may contribute to the apparent conservatism in the current design practice for large-diameter monopile foundations and to provide improved solutions on how to analyze and design the large-diameter monopiles for offshore wind turbine using the p-y method.
\end{abstract}

\section{Introduction}

Large-diameter monopile foundations offer several advantages as foundations for offshore wind-turbine generators (WTGs). Monopile foundations are very common and cost effectively installed in water depths of up to $30 \mathrm{~m}$ and having been used in over 75 percent of the offshore wind turbines installed in Europe. The installation of monopiles will face significant challenges when the pile diameter gets bigger and pile penetration gets deeper. Alternatively, steel-piled jacket foundations allow WTGs to be installed in much deeper waters (over $40 \mathrm{~m}$ ) compared to monopile foundations using currently available technology from the offshore industry. With more than $40 \%$ of the U.S. offshore wind resource located where the water is less than 30 meters (100 feet) deep, foundations fixed to the seafloor are still feasible and cost-effective in many locations

Wind turbine monopiles have a significantly larger diameter and smaller length to diameter ratio than typical piles used for offshore structures. The ratio of the length to the diameter for a monopile typically is also significantly smaller than those used in the American Petroleum Institute (API) load tests (Matlock, 1970 [1] and Reese et al., 1974 [2]). Therefore, the response of a monopile may be more like a rigid rotation, with components of resistance mobilized at the tip and axially along the sides as it rotates. This behaviour is in contrast to long slender piles that respond to lateral loading in bending rather than rotation. Those factors raise questions as to the suitability of current $\mathrm{p}$-y criteria for monopiles with a significantly larger diameter and smaller length to diameter ratio than typical piles used for deep foundations.

This paper discusses the factors that may contribute to the apparent conservatism in the current design practice for large-diameter monopile foundations. It provides improved solutions on the analysis and design of the large-diameter monopiles for offshore wind turbine using the $\mathrm{p}-\mathrm{y}$ method.

\section{The conventional $p-y$ curve method}

Several methods have been published in technical literature for the analysis of piles loaded by lateral force. In the past forty to fifty years the p-y method (or the $p-y$ curve method) which is based on Winkler foundation model has been widely accepted as a rational design method by engineers for both onshore and offshore applications. The p-y method idealizes the pile foundation as a beam resting on closely spaced independent soil springs as support (Fig. 1). When the elastic stiffness of the foundation can be considered constant with depth one can even obtain simple closed form solutions for the pile head stiffness and flexibility. However, the form of the soil springs (or subgrade reaction) is most difficult to quantify because the soil resistance is also a depth and dimension (pile diameter) dependent parameter which mostly relies on semiempirical formula

\footnotetext{
* Corresponding author: william.vanimpe@outlook.be
} 


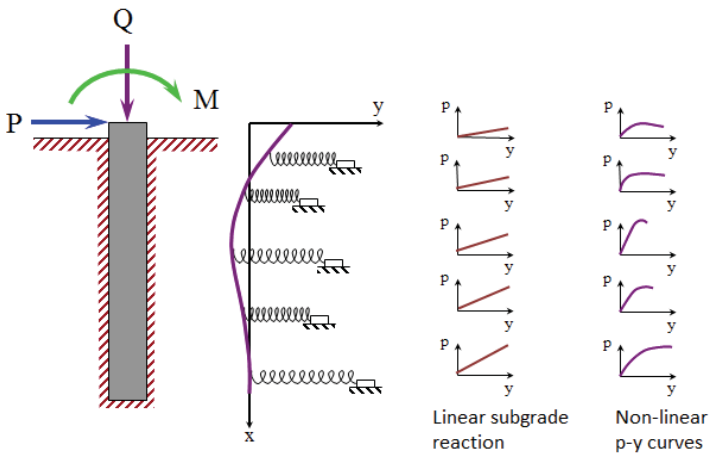

Fig. 1. Winkler model for piles with discretized subgrade reaction (p) corresponding to the pile lateral deflection $(y)$.

Many researches and field loading tests have been performed worldwide to provide guidance on how to estimate the nonlinear soil resistance $(\mathrm{p})$ versus the pile deflection (y) for a board range of soil and rock formations. The original $\mathrm{p}$-y curves were derived mostly for soil response on a single pile (Matlock, 1970 [1]; Reese et al., 1974 [2]; Reese et al. 1975 [3]; Reese and Welch, 1975 [4]). The p-y method using the Winkler model (Reese \& Van Impe, 2001, 2011 [5]) has been developed extensively to take into account the soilstructure interaction and nonlinear resistance of soils. The benefit of this method is significant because the engineer can intuitively check the solution by using basic engineering background on the simplified soil-structural model. Reese and Van Impe [5] presented the results of a number of case studies which were modelled using the p-y method and agreement between the experimental results and predicted results on the behaviour of test piles was found for a wide range of loads. The design and analysis cycles are dramatically reduced because of the ready-available soil parameters and the validated form of nonlinear soil resistance (Chen et al., 2010 [6])

\section{Considerations for piles with large diameter and short penetration}

Using large monopoles with pile diameters ranging from $4 \mathrm{~m}$ to $5 \mathrm{~m}$ for the offshore wind industry have become increasingly popular. It should be noted that the ratio of length to the diameter will typically be significantly smaller than those used for deriving widely-used $\mathrm{p}-\mathrm{y}$ curves. Large-diameter piles behave differently with the length over diameter ratio is less than 5 in that they tend to rotate and translate, instead of the conventional bending of long, slender piles (EPRI, 1982 [7]). The following factors may raise questions as to those piles with a significantly larger diameter and smaller length to diameter ratio than typical piles used for deep foundations.

\subsection{Effect of Side Friction on Pile Lateral Behaviour}

The response of a pile with a large diameter and short penetration may have more movement and rotation at the base, with components of resistance mobilized at the tip and axially along the sides as it rotates (Fig. 2). The assessment of the side friction through $\mathrm{t}-\mathrm{z}$ curves along the length of pile and its effect on the pile lateral response is one of the contributions as indicated in the figure.

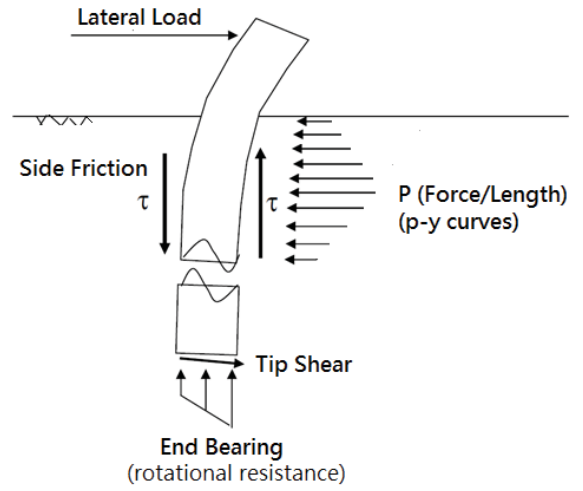

Fig. 2. Distribution of side shear stresses acting on a laterally loaded pile

The integrated side friction on the front side and the back side of the pile may generate a counter-balanced moment against the lateral loads at the pile top. However the development of unit skin friction will depend on the soil-pile interaction at the pile surface and the movement between the soil and pile in the axial direction. It may not be easy to catch the contribution quantitatively. On the other hand, since the semiempirical p-y curves were derived directly based on the field tests, the empirical p-y curve may include this sidefriction effect implicitly. The contribution of the side friction may be insignificant on the overall lateral soil resistance as derived from slender test piles with small pile diameters.

\subsection{Effect of Base Shear on Pile Lateral Behaviour}

The large diameter relatively short piles tend to rotate and/or translate instead of bending, evidenced by sizeable movements of the tip of the pile. There is an effect of base shear stresses which might add additional soil resistance for short rigid piles as shown in Fig. 3, in which the current p-y method does not consider. For the small-diameter piles, the shear resistance at the pile tip may not produce significant effect on the response. For a pile with a large diameter, the friction on the contact area between the pile tip and the pile tip soil can be modelled as a bi-linear spring as shown in Fig. 3. As a reasonable estimate, the friction may be fully mobilized if the pile tip moves laterally more than $5 \mathrm{~mm}$.

\subsection{Effect of Base Rotational Resistance on Pile Lateral Behaviour}

The end bearing developed at the base of the piles may resist well enough against rotation of the pile, which is acting as a rotational restraint. This behaviour is in 
contrast to long slender piles responding to lateral loading in bending rather than rotation. This additional rotational effect at the base is largely affected by the allowable bearing pressure developed at the pile tip and it was not considered as far by the current $p$-y method. Again, for the small-diameter slender piles, the rotational resistance at the pile tip indeed does not produce much effect on the response.

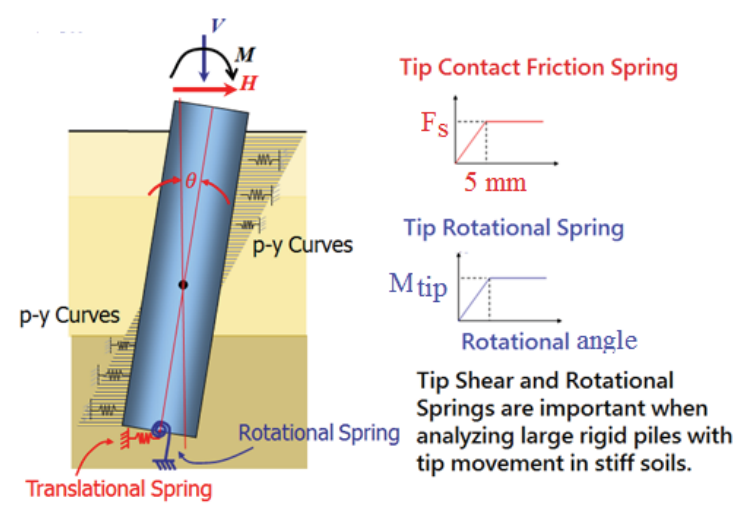

Fig. 3. Contribution of tip shear and tip rotation resistance on a laterally loaded pile

This rotational resistance at the base can be expressed as a rotational spring (moment versus rotational angle) as shown in Fig. 3. The moment resistance should be estimated by integrating the mobilized tip resistance on the contact area which may be less than the full tip area, depending on the pile stiffness itself and loads at the pile top.

The p-y method based on the beam-column model with discretized soil springs (reaction) however can be modified for taking into account those effects related to the large-diameter piles. The case studies presented in the next section will demonstrate the versatility of the p$\mathrm{y}$ method to meet the special features needed for analyzing the large-diameter piles under lateral loading. However, the designer is encouraged to calibrate those additional effects on the behaviour of a large-diameter pile based on field test data.

\section{Case studies}

A joint industry project, PISA (PIle Soil Analysis), was established in 2013 to develop new design methods specifically tailored for offshore wind turbine monopiles. This research is being conducted by an Academic Work Group (AWG), including researchers from University of Oxford and Imperial College London in United Kingdom, supported by the industrial consortium (Byrne et al, 2015, 2017 [8,9] and Beuckelaers, 2017 [10]). Two on-shore sites, representative of these materials, have been chosen for the field testing phase; (a) Cowden, a clay site in north-east England, and, (b) Dunkirk, a sand site in northern France. These sites represent the typical soil conditions found at many North Seawind farm sites. The test program is centered around a base pile geometry with a diameter of $0.762 \mathrm{~m}$ and a $\mathrm{L} / \mathrm{D}$ ratio of 5.25. From this base geometry, the diameter was varied for the large $(2.0 \mathrm{~m})$ and small $(0.273 \mathrm{~m})$ diameter field tests.

\subsection{Case 1 - Test piles at Cowden site}

Test Pile CM3 at Cowden site has a diameter of $0.762 \mathrm{~m}$ with 7.62-m embedment in stiff over-consolidated clay (Cowden Till). The wall thickness of this steel pile is 25 $\mathrm{mm}$. The length over diameter ratio (L/D) is 10 and is considered as a long and slender pile. The shear strength and initial shear modulus of Cowden Till is presented in Fig. 4.

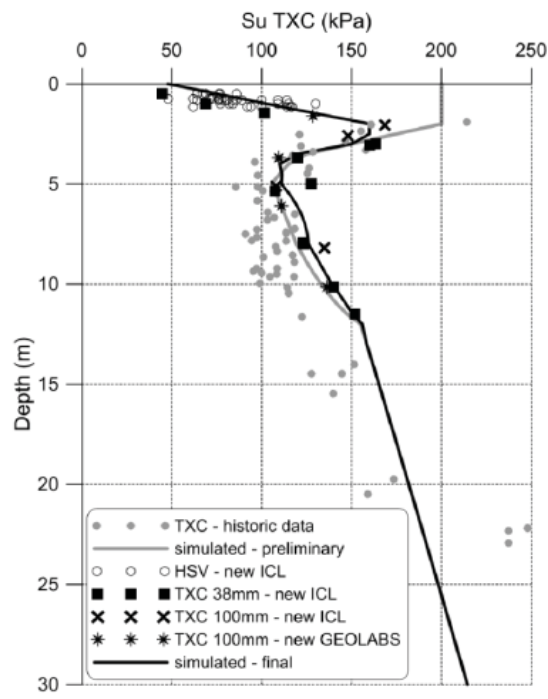

(a)

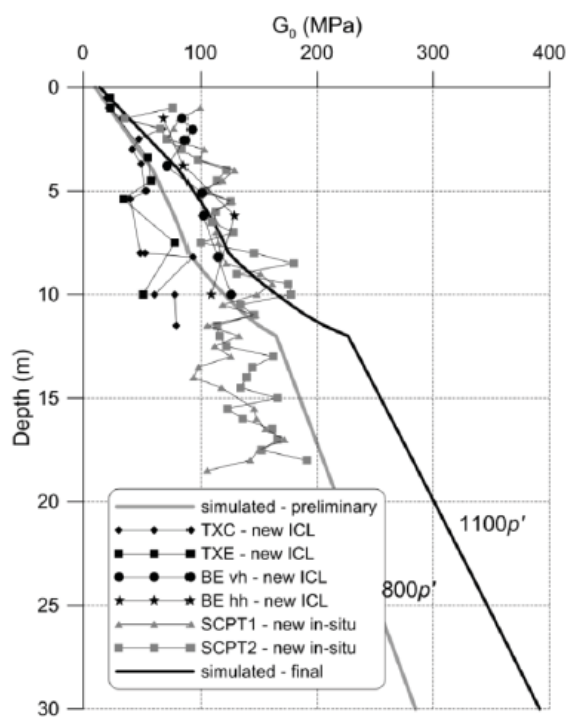

(b)

Fig. 4. Undrained shear strength and initial shear modulus of Cowden Till 
The lateral loads were applied at $10 \mathrm{~m}$ above the ground. As presented in Fig. 5(a) for Test Pile CM3 the measured deflection at the ground surface and the predicted deflection based on API clay criteria have a very close agreement. Since Test Pile CM3 is relative long pile, the tip shear did not add noticeable contribution on the overall lateral resistance.

Test Pile CL2 at Cowden site has a diameter of $2.0 \mathrm{~m}$ with $10.5-\mathrm{m}$ embedment in the same Cowden Till. The wall thickness of this steel pile is $25 \mathrm{~mm}$. The length over diameter ratio $(\mathrm{L} / \mathrm{D})$ is 5.25 and is considered as a relatively short pile. The lateral loads were also applied at $10 \mathrm{~m}$ above the ground. As presented in Fig. 5(b) the measured deflection at the ground surface and the predicted deflection based on API clay criteria do not really match for this case. Since Test Pile CL2 is relatively short pile with a large diameter, considering the contribution from the tip shear resistance, tip rotation resistance, and the side friction resistance is absolutely necessary as demonstrated in Fig. 5(b). In this case the contribution from the side friction generating momentcouple is more significant than those from the tip rotation as well as tip shear.
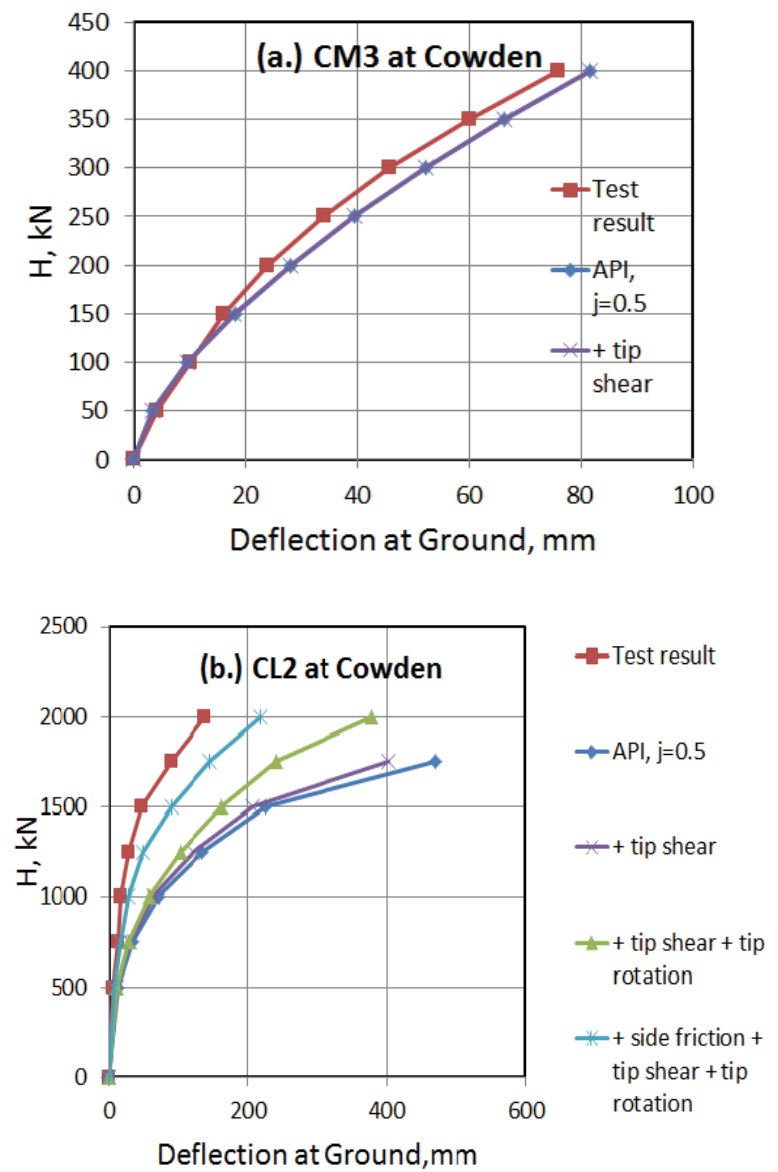

Fig. 5. Comparison between the measured and the predicted deflections at the ground level for Test Piles CM3 and CL2 at Cowden site

\subsection{Case 2 - Test piles at Dunkirk site}

Test Pile DM6 at Dunkirk site has a diameter of $0.762 \mathrm{~m}$ with 4-m embedment in the dense marine sand which belongs to Flandrian deposit. The unit weight of sand is $19 \mathrm{kN} / \mathrm{m}^{3}$ and the internal friction angle is $39.5^{\circ}$. The ground water level is estimated at a depth of $5.4 \mathrm{~m}$ below the grade. Based on the recommendation of API sand criteria, values of the initial soil p-y modulus $\left(\mathrm{k}_{\mathrm{py}}\right)$ are 66.7 MN/m $/ \mathrm{m}^{3}$ and $37.8 \mathrm{MN} / \mathrm{m}^{3}$ for sands above and below the water table, respectively. The wall thickness of this steel pipe pile is $19 \mathrm{~mm}$ with the length over diameter ratio (L/D) of 5.25. The lateral loads were applied at 10 $\mathrm{m}$ above the ground. As presented in Fig. 6 (a) the predicted deflection based on API sand criteria is reasonable close to the measured deflection up to $100 \mathrm{kN}$ of lateral loads and at the conservative side. The pile yields to an excessive deflection under a lateral load of $150 \mathrm{kN}$ based on API sand criteria. The side friction and tip restraint (tip shear and tip rotation-resistance) did not add noticeable contribution on the overall lateral resistance. The effective stress along the embedded pile is an important factor in developing side friction and tip resistance. However, the effective stress for the test pile with $4 \mathrm{~m}$ of penetration is not significant in generating large resistant components.

Test Pile DL2 at Dunkirk site has a diameter of $2.0 \mathrm{~m}$ with $10.5-\mathrm{m}$ embedment in the same Flandrian deposit. The wall thickness of this steel pile is $38 \mathrm{~mm}$. The length over diameter ratio (L/D) is 5.25. The lateral loads were also applied at $10 \mathrm{~m}$ above the ground. As presented in Fig. 6(b) the measured deflection at the ground surface and the predicted deflection based on API sand criteria have a close agreement up to $1500 \mathrm{kN}$ of lateral loads. API sand criteria may generate higher soil resistance for a large-diameter pile at a higher loading range. It is likely that the empirical parameter "A" used for modifying the ultimate soil resistance and the initial soil $\mathrm{p}-\mathrm{y}$ modulus $\left(\mathrm{k}_{\mathrm{py}}\right)$ for controlling the initial stiffness in API equations for generating p-y curves in sand should be studied further for large-diameter piles. Similar to Test Pile DM6 the side friction and tip restraint (tip shear and tip rotation-resistance) did not add noticeable contribution on the overall lateral resistance for this test pile because of the insignificant effective stress.

Based on the above two cases with pile diameters of $0.762 \mathrm{~m}$ and $2 \mathrm{~m}$, API sand criteria may under-predict the lateral capacity for slender piles at large deflections. On the other hand, API sand criteria may over-predict the lateral capacity for piles with large diameters at higher deflections. 

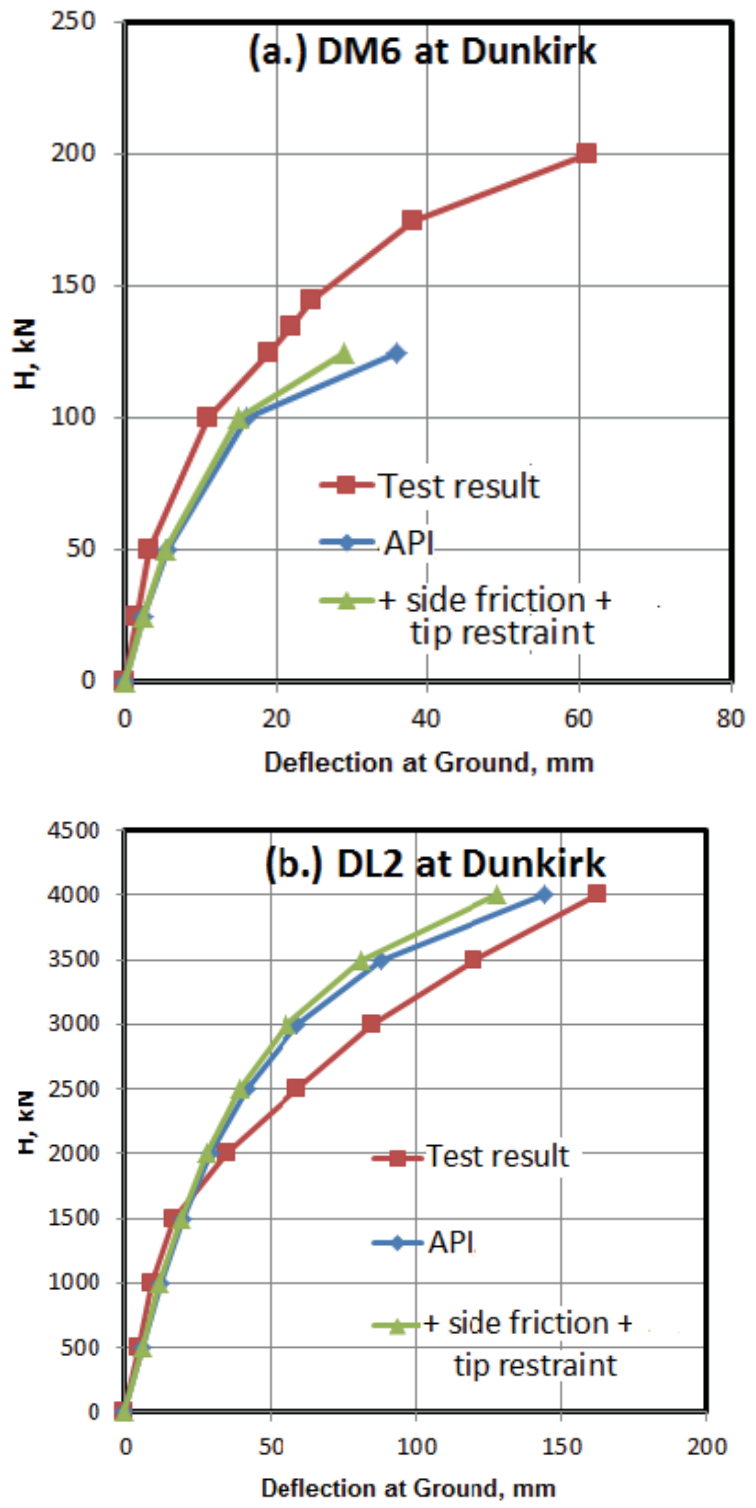

Fig. 6. Comparison between the measured and the predicted deflection at the ground level for Test Piles DM6 and DL2 at Dunkirk site

\section{Conclusions and recommendations}

The p-y curve method was developed based on the commonly-recognized structural theory. With the p-y curve method, both equilibrium and compatibility are automatically satisfied when the solution converges. The distribution of the soil pressure and soil resistance is rationally based on the field-validated p-y curves. The p$y$ method can be used for analysis and design of largediameter monopiles by adding contribution from tip shear, tip rotation-resistance, and the moment couple from the side friction and adjustments on the initial soil p-y modulus and the ultimate soil resistance in API sand criteria. The field tests and monitoring programs can provide engineers with valuable data for improvement of the p-y method, especially for special soil formations and large-size piles.

\section{References}

1. H. Matlock, "Correlations for Design of LaterallyLoaded Piles in Soft Clay," Paper No. OTC 1204, Proceedings, Second Annual Offshore Technology Conference, Houston, Texas, Vol. 1, 1970, pp. 577594.

2. L. C. Reese, W. R. Cox, and F. D. Koop, "Analysis of Laterally Loaded Piles in Sand," Paper No. OTC 2080, Proceedings, Fifth Annual Offshore Technology Conference, Houston, Texas, 1974 (GESA Report No. D-75-9).

3. L. C. Reese, W. R. Cox, and F. D. Koop, "Field Testing and Analysis of Laterally Loaded Piles in Stiff Clay," Paper No. OTC 2313, Proceedings, Seventh Offshore Technology Conference, Houston, Texas, (1975).

4. L. C. Reese, and R. C. Welch, "Lateral Loading of Deep Foundations in Stiff Clay," Journal of the Geotechnical Engineering Division, ASCE, Vol. 101, No. GT7, pp. 633-649. (1975)

5. L. C. Reese, and W. F. Van Impe, Single Piles and Pile Groups Under Lateral Loading, 2nd Edition, A Balkema Book, CRC Press, Taylor \& Francis Group. $(2001,2011)$

6. J. Chen, E. Farouz, and P. Landers, "Development of Project-Specific p-y Curves for Drilled Shaft Retaining Wall Design," Proceedings of Earth Retention Conference 3, ASCE, Bellevue, Washington, pp. 162-169. (2010)

7. Electric Power Research Institute (EPRI), Laterally Loaded Pile Drilled Pier Research, Volume 2: Research Documentation by GAI Consultants, Inc., (1982)

8. B. W. Byrne, R. McAdam, H. J. Burd, G. T. Houlsby, C. M. Martin, L. Zdravkovi c, D. M. G. Tarboda, D. M. Potts, R. J. Jardine, M. Sideri, F. C. Schroeder, K. Gavin, P. Doherty, D. Igoe, A. Muir Wood, D. Kallehave and J. Skov Gretlund, New design methods for large diameter piles under lateral loading for offshore wind applications, in 'Proceedings of the 3rd International Symposium on Frontiers in Offshore Geotechnics (ISFOG)', CRC Press, Oslo, Norway, pp. 705-710. (2015)

9. B. W. Byrne, R. McAdam, H. J. Burd, G. T. Houlsby, C. M. Martin, W. J. A. P. Beuckelaers, L. Zdravkovi_c, D. M. G. Tarboda, D. M. Potts, R. J. Jardine, E. Ushev, T. Liu, D. Abadias, K. Gavin, D. Igoe, P. Doherty, J. Skov Gretlund, M. Pacheco Andrade, A. Muir Wood, F. C. Schroeder, S. Turner and M. A. L. Plummer, PISA: new design methods for offshore wind turbine monopiles, in 'Proceedings of the 8th Offshore Site Investigation \& Geotechnics (OSIG) International Conference', London, U.K. (2017)

10. W. J. Beuckelaers, Numerical Modelling of Laterally Loaded Piles for Offshore Wind Turbines, A thesis submitted for the degree of Doctor of Philosophy, University of Oxford, U.K. (2017) 